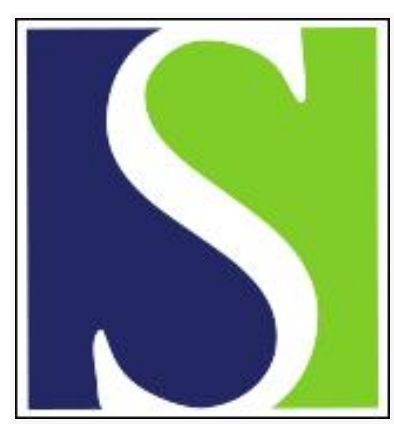

Scand J Work Environ Health 1980;6(3):221-226

https://doi.org/10.5271/sjweh.2610

Issue date: Sep 1980

Mutagenic action of isocyanates used in the production of polyurethanes.

by Andersen M, Binderup M-L, Kiel P, Larsen H, Maxild J

The following articles refer to this text: 1982;8(1):80-81;

$1981 ; 7(3): 237-238$

Key terms: Salmonella typhimurium; 4,4'-methylenediphenylisocyanate; aromatic amine; carcinogen; isocyanate; MDI; mutagene; mutagenic action; polyurethane; TDI; toluene diisocyanate

This article in PubMed: www.ncbi.nlm.nih.gov/pubmed/7010247 


\title{
Mutagenic action of isocyanates used in the production of polyurethanes
}

\author{
by Margrethe Andersen, technician, Mona-Lise Binderup, MSc, \\ Pauli Kiel, PhD, Henry Larsen, MSc, Jette Maxild, MSc ${ }^{1}$
}

\begin{abstract}
ANDERSEN M, BINDERUP M-L, KIEL P, LARSEN H, MAXILD J. Mutagenic action of isocyanates used in the production of polyurethanes. Scand $j$ work environ health 6 (1980) 221-226. Isocyanates used in the production of polyurethanes were investigated for mutagenic action in Salmonella typhimurium. These investigations showed that the most commonly used isocyanates, toluene disocyanate (TDI) and 4,4'-methylenediphenylisocyanate (MDI), are mutagenic. This effect can be ascribed to the amine analogues formed during the hydrolysis of isocyanates: TDI is mutagenic in TA 1538 and TA 98 after metabolic activation. This finding agrees with the results obtained with the amine analogue 2,4-toluenediamine. MDI, like the amine analogue $4,4^{\prime}-$ meth- $^{\prime}$ ylenedianiline, is mutagenic in TA 100 after metabolic activation by rat liver enzymes (S-9 mix). A prepolymerized polyisocyanate of the MDI type is also mutagenic in assays using TA 100 and S-9 mix. It is concluded that isocyanates are potentially mutagenic and carcinogenic to man. In view of their widespread use in the work environment and in light of the high production figures for polyurethanes in industrialized countries, isocyanates must be considered to represent a serious health hazard.
\end{abstract}

Key terms: aromatic amines, carcinogens, 4,4'-methylenediphenylisocyanate (MDI), mutagens, Salmonella typhimurium, toluene diisocyanate (TDI).

In $1977,1.7$ million tons of polyurethanes were produced in the United States (20), Europe (19), and Japan (18). An annual increase of $7 \%$ is expected in the United States during the next 5-a period. For use in the building industry, for insulation material alone, the increase will be $15 \%$ yearly (17).

Polyurethane is a kind of "superplastic" which can be adapted for many purposes. It can take the form of flexible and rigid foams suitable for use in coating and insulation. It may be compact, eg, for the manufacture of soles of shoes and rollers, or it may be used as fiber, in lacquers, or as glue, adhesives and binding agents in coating materials.

1 The authors comprise the group called Mutagengruppen and are listed in alphabetical order.

Reprint requests to: Mutagengruppen, The Royal Danish School of Pharmacy, Department of Microbiology, 2 Universitetsparken, DK-2100 Copenhagen $\varnothing$, Denmark.
Isocyanates are the basic material for the production of polyurethane. They are strongly reactive substances known to cause irritation and to have allergenic effects (11). Until recently, no literature has been published concerning the possible carcinogenic and mutagenic effects of isocyanates $(11,15)$.

In this report a study of the mutagenic action of isocyanates in Salmonella typhimurium is presented, the primary target being the isocyanates used for the production of polyurethanes.

\section{Material and methods}

\section{Isocyanates}

Phenyl isocyanates of analytical grade from Merck was used. The toluene diisocyanate (TDI) used was the commercial product Desmodur T 80 (Bayer AG), which is a mixture of 2,4- and 2,6-toluene diisocyanate (ratio 80:20). Desmodur $L$ and 
E1361 (Bayer AG) are commercial polyisocyanates of the TDI type. They contain $33-39 \%$ solvent consisting of 2-ethoxyethyl acetate and xylene at a 1:1 ratio. 1-Naphthylisocyanate, 4,4'-methylenediphenylisocyanate (MDI), and 1,6-hexanediisocyanate (HDI) were synthetic grade from Merck-Schuchardt. Caradate 30 (Shell Chemicals) is commercial MDI, technical grade. Desmodur E 21 (Bayer AG) is prepolymerized polyisocyanate of the MDI type. Table 1 shows the structural formulas of the isocyanates under study.

\section{Aromatic amines}

As positive controls in the mutagenicity testing, 2,4-toluenediamine (Fluka, practical grade) and 4,4'-methylenedianiline (Merck-Schuchardt, synthetic grade) were used.

\section{Solvents}

Dimethyl sulfoxide (Merck, spectrometric grade) was used as the solvent and negative control in the mutagenicity testing. The negative control for Desmodur $L$ and E1361 was a solvent prepared from equal parts of 2-ethoxyethyl acetate (MerckSchuchardt, synthetic grade) and xylene (technical grade). This mixture was dissolved in dimethyl sulfoxide to give a concentration of $35 \%$.

\section{Mutagenicity testing}

The plate incorporation assay using histidine-requiring mutants of $S$. typhimurium was carried out, without modification, as described by Ames et al (1). The tests were performed with test strains TA 100 (reverting by base-pair substitution), TA 98, TA 1537, and TA 1538 (reverting by frameshift) both with and without the addition of the rat liver microsome fraction S-9 mix. Rat liver enzymes were induced by $0.1 \%$ sodium phenobarbital in the drinking water one week before the rats

Table 1. Structural formulas of the isocyanates tested in the Salmonella/microsome mutagenicity test.

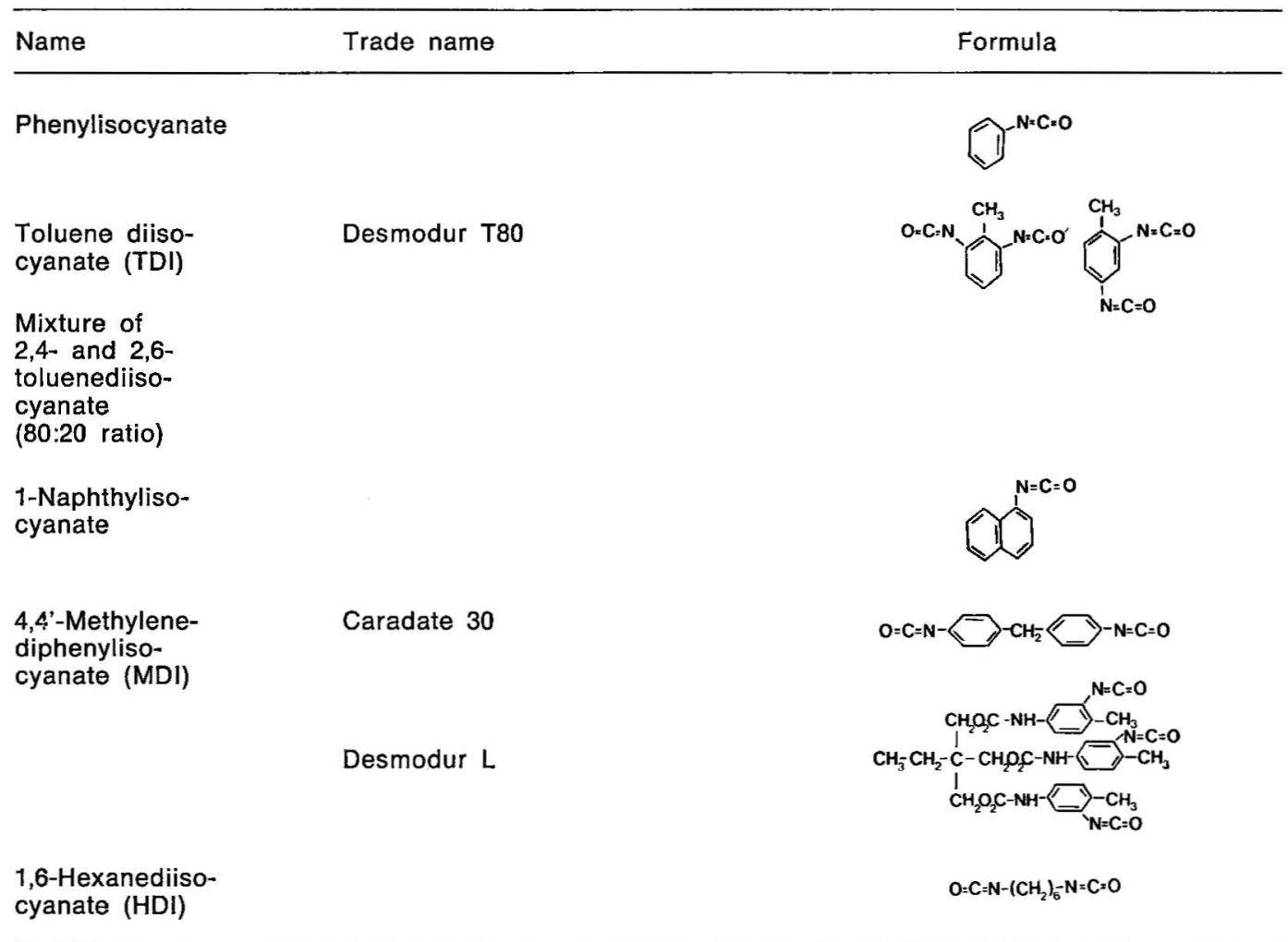


Table 2. The mutagenic action of simple isocyanates in the Salmonella/microsome mutagenicity test.a

\begin{tabular}{|c|c|c|c|c|c|c|c|c|}
\hline \multirow{2}{*}{ Isocyanate } & \multicolumn{4}{|c|}{$+S-9$ mix } & \multicolumn{4}{|c|}{ - S-9 mix } \\
\hline & TA 100 & TA 98 & TA 1537 & TA 1538 & TA 100 & TA 98 & TA 1537 & TA 1538 \\
\hline Phenylisocyanate & - & - & - & $N D^{b}$ & - & 一 & - & ND \\
\hline $\begin{array}{l}\text { Toluene diisocyanate } \\
\text { (TDI) }\end{array}$ & + & + & - & + & - & - & - & - \\
\hline $\begin{array}{l}\text { 1-Naphthyliso- } \\
\text { cyanate }\end{array}$ & + & - & - & ND & - & - & - & ND \\
\hline $\begin{array}{l}\text { 4,4'-Methylene- } \\
\text { diphenylisocyanate } \\
\text { (MDI) }\end{array}$ & + & + & - & ND & - & - & - & ND \\
\hline $\begin{array}{l}\text { 1,6-Hexanediiso- } \\
\text { cyanate (HDI) }\end{array}$ & - & - & - & ND & - & - & - & ND \\
\hline
\end{tabular}

a The isocyanates were incorporated into the agar overlay in a wide dose range up to the highest noninhibitory dose. The result was classified as positive if the number of revertant colonies on each plate was more than twice the spontaneous number and if that number increased as the dose increased.

b $\mathrm{ND}=$ not determined.

were killed. The rat liver microsome fraction S-9 and the NADPH-generating ${ }^{2}$ system were prepared according to Ames et al (1). One hundred and fifty microliters of S-9 were added to each plate. Isocyanates and controls were dissolved in $100 \mu \mathrm{l}$ of dimethyl sulfoxide and incorporated in the agar overlay. Three to five plates were prepared from each compound and dose. Since isocyanates are volatile chemical compounds, these plates, containing the same dose and compound, were placed in polyethylene bags. The polyethylene bags were sealed and incubated at $37^{\circ} \mathrm{C}$ for $48 \mathrm{~h}$.

\section{Results}

A number of simple isocyanates were studied in plate incorporation assays using histidine-requiring mutants of $S$. typhimurium. The results of these assays are shown in table 2. TDI, 1-naphthylisocyanate, and MDI were mutagenic after metabolic activation.

TDI and MDI are the isocyanates most commonly used in the production of polyurethanes. Table 3 shows the results of the assays with TA 98 and the S-9

$2 \mathrm{NADPH}=$ reduced form of nicotinamide adenine dinucleotide phosphate. mix for the TDI product Desmodur T 80 and two polyisocyanates of the TDI type, Desmodur L and E1361. Desmodur E1361 is prepolymerized, but is otherwise identical to Desmodur L. The positive control used was 2,4-toluenediamine, which is the amine analogue to the 2,4-isomer in TDI. Solutions of Desmodur L and E1361 are available only in a mixture of xylene and 2-ethoxyethyl acetate, and thus a suitable concentration of this mixture was used as the negative control for these two polyisocyanates. Only Desmodur $\mathrm{T} \mathbf{8 0}$ was mutagenic. This mutagenicity could be demonstrated in a narrow dose range only, since concentrations exceeding $500 \mu \mathrm{g}$ per plate inhibited the bacterial growth. A corresponding inhibitory effect was not found for the amine analogue 2,4-toluenediamine. In the case of all doses of Desmodur T 80 and 2,4-toluenediamine, it was insured that the $150 \mu \mathrm{l}$ of S-9 used per plate was an optimal concentration.

Fig 1 presents the dose-response curves for the MDI product, Caradate 30 , and a prepolymerized polyisocyanate of the MDI type, Desmodur E21. Assays were carried out in TA 100 with the addition of S-9 mix. The MDI amine analogue 4,4'methylenedianiline was included as a positive control. All the products examined were mutagenic. The number of induced revertant colonies per plate increased as 
the dose increased. The dose-response curves were rectilinear up to a dose of $50 \mu \mathrm{g}$ per plate for Caradate 30 and $100 \mu \mathrm{g}$ per plate for Desmodur E21. A comparison of the curves of these two isocyanates with those of the MDI amine analogue showed that at $50 \mu \mathrm{g}$ the effect of Caradate 30 was $72 \%$, and that of Desmodur E21 $13 \%$, of the effect measured for $50 \mu \mathrm{g}(0.25$ $\mu \mathrm{mol})$ of MDA. A check was made to insure that the $150 \mu \mathrm{l}$ of S-9 used per plate was an optimal concentration. The results indicate that MDI products, such as Caradate 30 , can be hydrolyzed almost completely to the amine analogue.

In order to affirm that the mutagenic effect was not due to interaction between MDI and dimethyl sulfoxide, which is normally used as a solvent in plate incorporation assays, we tested Caradate 30 after direct incorporation into the top agar layer. By this means, 10 and $100 \mathrm{mg}$ of the compound induced 300 and 800 revertant colonies per plate, respectively (in addition to the number of spontaneous ones).

\section{Discussion}

The results show that the isocyanates most commonly used for the production of polyurethanes, TDI and MDI, are mutagenic in $S$. typhimurium. It was also demonstrated that a prepolymerized polyisocyanate of the MDI type is mutagenic. As an agreement has been established between mutagenic action in Salmonella and carcinogenic effect in animals $(9,10)$, the tested isocyanates must be considered potentially carcinogenic to man.

Isocyanates react with active hydrogen in, eg, water, amines, and proteins. With water they form the following analogous amines (13):

$\mathrm{RN}=\mathrm{C}=\mathrm{O}+\mathrm{HOH} \rightarrow \mathrm{RNHCOOH} \rightarrow \mathrm{RNH}_{2}+\mathrm{CO}_{2}$.

The reaction may occur when isocyanate vapors or aerosols are caught on moist surfaces, skin, or the respiratory mucosa. This possibility has previously been pointed out in connection with allergic skin diseases induced by MDI (2).

Table 3. Mutagenic action of isocyanates of the toluene disocyanate (TDI) type for $S$ typhimurium TA 98 in the plate incorporation assay performed with the addition of rat liver microsome fraction (1).

\begin{tabular}{|c|c|c|c|c|}
\hline \multirow{2}{*}{$\begin{array}{l}\text { Compound } \\
\\
\text { Desmodur T80 }\end{array}$} & \multicolumn{2}{|c|}{ Dose ( $\mu \mathrm{g} / \mathrm{plate})$} & \multicolumn{2}{|c|}{$\begin{array}{l}\text { Number of revertant } \\
\text { colonies per plate }\end{array}$} \\
\hline & $\begin{array}{r}125 \\
250 \\
500 \\
1,000\end{array}$ & & $\begin{array}{r}80 \\
113 \\
156 \\
114\end{array}$ & $\begin{array}{l}(63-93) \\
(82-144) \\
(129-184) \\
(99-128)\end{array}$ \\
\hline Desmodur L & 1,000 & & 28 & $(21-34)$ \\
\hline $\begin{array}{l}\text { Desmodur E1361 } \\
\text { (prepolymerized L) }\end{array}$ & 2,000 & & 32 & $(28-41)$ \\
\hline $\begin{array}{l}\text { Solvent } 35 \% \mathrm{o} \\
\text { (negative control for } \\
\text { Desmodur L and E1361) }\end{array}$ & 2,000 & & 28 & $(20-37)$ \\
\hline $\begin{array}{l}\text { 2,4-Toluenediamine } \\
\text { (positive control) }\end{array}$ & $\begin{array}{r}12.5 \\
25.0 \\
50.0 \\
100\end{array}$ & $\begin{array}{l}(0.10 \mu \mathrm{mol}) \\
(0.20 \mu \mathrm{mol}) \\
(0.41 \mu \mathrm{mol}) \\
(0.82 \mu \mathrm{mol})\end{array}$ & $\begin{array}{r}48 \\
78 \\
133 \\
281\end{array}$ & $\begin{array}{l}(41-56) \\
(76-79) \\
(112-157) \\
(221-330)\end{array}$ \\
\hline $\begin{array}{l}\text { Dimethyl sulfoxide } \\
\text { (negative control) }\end{array}$ & & & 30 & $(28-32)$ \\
\hline
\end{tabular}

a Each figure is an average of numbers scored on three to five plates. The figures in parentheses are the lowest and highest values obtained with each dose. The figures are in italics if the number of revertant colonies on each plate averaged more than twice the number obtained for the negative control. Desmodur $L$ and $E 1361$ were tested in the maximum noninhibitory dose.

b The negative control for Desmodur L and E1361 was a solvent prepared from equal parts of 2-ethoxyethyl acetate and xylene. This mixture was dissolved in dimethyl sulfoxide to give a concentration of $35 \%$. 
Furthermore it has been demonstrated that polyurethane produced from MDI is hydrolyzed by autoclaving in an aqueous solution, and it gives off the aromatic amine analogue 4,4'-methylenedianiline (4). After metabolic activation, this aromatic amine is mutagenic in $S$. typhimurium TA 100 and TA $98(4,8)$.

2,4-Toluenediamine, the TDI amine analogue, is mutagenic in test strains TA 100 and TA 1538 after metabolic activation (9). 1-Naphthylamine, the amine analogue of 1-naphthylisocyanate, is mutagenic in test strains TA 100 and TA 98 after metabolic activation (9). Aniline, the amine analogue of phenylisocyanate, is not mutagenic in the standard plate incorporation assay (9). No information is, as far as we know, available about the mutagenic action of 1,6-hexanediamine, the amine analogue of HDI. The fact that the isocyanates were mutagenic in the same test strains as the amine analogues and that the isocyanates which gave a nonpositive result were analogous to amines for which no positive results were found in $S$. typhimurium may indicate that the mutagenic effect is due to the hydrolytic products, the aromatic amine analogues.

It is known that aromatic amines such as naphtylamine and benzidine have caused cancer of the bladder in man (3). Among a number of other aromatic amines the TDI amine analogue, 2,4-toluenediamine, and the MDI amine analogue, 4,4'-methylenedianiline, have been shown to produce cancer in rats $(7,12,14,16)$.

In work environments high concentrations of isocyanate may be present. The vapor pressure of the most commonly used isocyanate, TDI, is high, viz, $2.3 \times$ $10^{-2} \mathrm{~mm} \mathrm{Hg}$ at $25^{\circ} \mathrm{C}$ (6). This level corresponds to $30 \mathrm{ppm}$, and therefore maintaining a low concentration in the air of a workplace is difficult. The problem is further intensified when materials are applied by spraying, which results in aerosol formation. When MDI is sprayed on walls, its concentration in the air is $\mathbf{3 5 0}$ times greater than when it is applied with a brush (6). Moreover, the formation of polyurethane foam is an exothermal process (6). The generation of heat leads to an increased release of nonreacted isocyanate from the foam.

When polyurethanes are pyrolyzed,

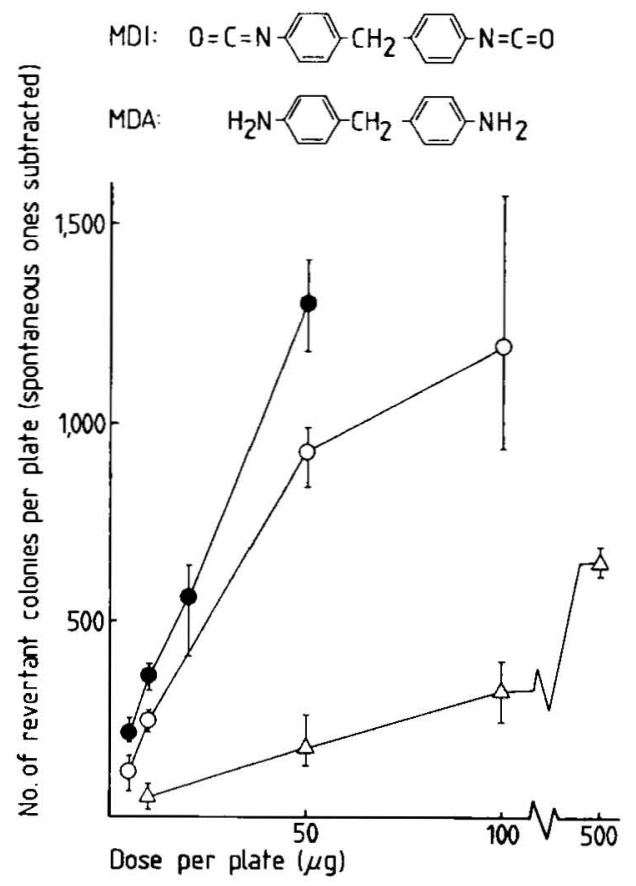

Fig 1. Mutagenic action of isocyanates of the 4,4'-methylenediphenylisocyanate (MDI) type for $S$ typhimurium TA 100 in the plate incorporation assay performed with the addition of the rat liver microsome preparation $\mathrm{S}-9 \mathrm{mix}$ (1). 4,4'Methylenedianiline, the amine analogue of MDI, was included as a positive control. The number of spontaneous revertant colonies per plate was estimated at 198. Each point is an average of numbers scored on three plates. The limits of the vertical lines indicate the lowest and highest values obtained with each dose. [O Caradate 30 (MDI), $\triangle$ Desmodur E21, a prepolymerized polyisocyanate of the MDI type, 4,4'-methylenedianiline (MDA)].

appreciable quantities of the corresponding diisocyanates are formed (13). The same may be the case, eg, when polyurethane burns during the process of cutting coated plates with a blowpipe or welding on tubes preinsulated with polyurethane.

Even when the present threshold limit values are observed, workers producing polyurethane will be exposed to quantities of isocyanate which are mutagenic in bacteria in the Salmonella/microsome mutagenicity test. ${ }^{3}$

3 The present Danish threshold limit values (TLVs) for TDI and MDI are $0.01 \mathrm{ppm}$ or 70 and $100 \mu \mathrm{g} / \mathrm{m}^{3}$, respectively (5). If a worker inhales 401 of $\mathrm{air} / \mathrm{min}$, the TLVs permit that he be exposed to $1 \mathrm{mg}$ of TDI or $1.4 \mathrm{mg}$ of MDI in the course of a workday (6 h). 
In view of the very high production figures for polyurethanes, it must be feared that a large number of workers are at present being exposed to isocyanates and thus also to a potential risk of cancer and genetic damage.

\section{Acknowledgment}

This study was supported by the Danish Medical Research Council.

\section{References}

1. Ames BN, McCann J, Yamasaki E. Methods for detecting carcinogens and mutagens with Salmonella/mammalian-microsome mutagenicity test. Mutat res 31 (1975) 347 -364 .

2. Behrbohm P. Arbeithygiene und Arbeitsschutz bei der Anwendung von Anstrichstoffen und Lösemitteln im Bauwesen. Arbeitshygienische Inf Bauwesen DDR 9 (1973) 93-102.

3. Case RAM, Hosker ME, McDonald DB, Pearson JT. Tumors of the urinary bladder in workmen engaged in the manufacture and use of certain dyestuff intermediates in the British chemical industry. $\mathrm{Br} \mathrm{j}$ ind med 11 (1954) 75-104.

4. Darby TD, Johnson HJ, Northup SJ. An evaluation of a polyurethane for use as a medical grade plastic. Toxicol appl pharmacol 46 (1978) $449-453$.

5. Directorate for Labour Inspection Service. Threshold limit values. Copenhagen 1979. (Publ no 62).

6. Hampton HA, Hurd $\mathbf{R}$, Shearing $\mathrm{HJ}$. Recent developments in polyurethanes. $J$ oil colour chem assoc 43 (1960) 96-123.

7. Ito $\mathrm{N}$, Hiasa $\mathrm{Y}$, Konishi $\mathrm{Y}$, Marugami $\mathbf{M}$. The development of carcinoma in liver of rats treated with $\mathrm{m}$-toluylenediamine and the synergistic and antagonistic effects with other chemicals. Cancer res 29 (1969) $1137-1145$.

8. LaVoie E, Tulley L, Fow E, Hoffmann D. Mutagenicity of aminobiphenyl and nitrophenyl ethers, sulfides and disulfides. Mutat res 67 (1979) 123-131.

9. McCann J, Choi E, Yamasaki E, Ames BN. Detection of carcinogens as mutagens in the Salmonella/microsome test: Assay of 300 chemicals. Proc nat acad sci usa 72 (1975) $5135-5139$.

10. McCann J, Ames BN. Detection of carcinogens as mutagens in the Salmonella/ microsome test: Assay of 300 chemicals: Discussion. Proc nat acad sci usa 73 (1976) 950-954.

11. National Institute for Occupational Safety and Health. Criteria for a recommended standard ...... Occupational exposure to toluene diisocyanate. U.S. Department of Health, Education and Welfare, Public Health Service, 1973, pp 23-31.

12. Schoental $R$. Carcinogenic and chronic effects of 4,4'-diaminodiphenylmethane, an epoxyresin hardener. Nature 219 (1968) $1162-1163$.

13. Seeman J, Wölcke U. Über die Bildung toxicher Isocyanatdämpfe bei der thermischen Zersetzung von Polyurethanlacken und ihren polyfunktionellen Härtern. Zentralbl Arbeitsmed Arbeitsschutz Prophyl 26 (1976) 2-9.

14. Steinhoff D, Grundmann E. Zur cancerogenen Wirkung von 4,4'-diaminodiphenylmethan und 2,4'-diaminodiphenylmethan Naturwissenschaften 57 (1970) 247-248.

15. Walpole AL, Williams MHC. Toxicity of some cross-linking agents. $J$ oil colour chem assoc 42 (1959) 694-705.

16. - DuPont notifies NIOSH of experimental carcinogenicity of MTD. Occup health saf lett (1975): 5, 3-4.

17. U US polyurethane outlook. Eur chem news March 31 (1978) 10.

18. - Japan 1977: A persistent lowgrowth economy dictates new shifts strategy. Mod plast int Jan(1978)14.

19. Europe waits for a turnaround. Mod plast int Jan(1978)18.

20. _- US plastics sales 1977. Mod plast int Jan(1978)43.

Received for publication: 13 February 1980. 